Wiener Klinisches Magazin 2014 · 17:3

DOI 10.1007/s00740-014-0235-7

๑) Springer-Verlag Wien 2014

\section{Kienast}

Springer-Verlag, Wien

\title{
Aus den Zwischenwelten
}

Einen gewagten Einfall hatte der junge italienische Regisseur Romeo Castellucci in der Wiener Festwochenproduktion von Christoph Willibald Glucks Oper „Orfeo ed Euridice“: Parallel zur Geschichte des ins Totenreich hinabsteigenden Orfeo, der von dort seine geliebte Frau Euridice zurück ins Leben holen möchte, erzählte er die Geschichte einer jungen Frau, die aufgrund einer Herzrhythmusstörung einen Herzstillstand erlitt und seit drei Jahren im Geriatriezentrum am Wienerwald im Wachkoma liegt. Die rückgekoppelte Verbindung zwischen dem Geschehen auf der Bühne der Halle E im Museumsquartier und dem hochtechnisch ausgestatteten Krankenzimmer in Hietzing erzeugte dabei eine intensiv berührende Atmosphäre: Die Patientin, die vor ihrem Krankheitsereignis selbst klassisches Ballett ausübte, hört über Kopfhörer Musik und Gesang der Aufführung, Das Publikum - und die Schauspieler - sehen den Weg zum Krankenbett über eine überlebensgroße Projektion während der gesamten Vorstellung und am dramatischen Höhepunkt die junge Frau selbst, ihre wachen, aufmerksamen und traurigen Augen.

\section{Was wissen wir schon von den Zwischenwelten...}

Der Vergleich der "Zwischenreiche" in der Mythologie und dem realen Leben scheint durchaus berechtigt und er bietet ein ganzes Paket an Denkanstößen. Mit allen ihm zur Verfügung stehenden Mitteln möchte Orpheus seine Euridice zurückholen aus dem Reich des Todes, er kann ihren Tod nicht akzeptieren und er rührt mit seiner Trauer schließlich auch Amor, der ihm gestattet die Grenze zwischen Leben und Tod mit der Aussicht auf Rückkehr zu überschreiten. Das Verbot, sich beim gemeinsamen Weg mit seiner Geliebten zurück ins Leben nach ihr umzusehen - und auch keine Erklärung dafür zu geben - wird ihm zum Verhängnis. Auf Drängen Euridices, die seine Distanzierung nicht versteht, gibt er nach - und verliert sie endgültig. Die Kommunikation zwischen den unterschiedlichen Wahrnehmungswelten unterliegt anderen Mechanismen: Euridice ist sich gar nicht sicher, ob sie wieder zurück will noch dazu, wo sie Orpheus' Liebe durch seine Zurückhaltung vermeintlich als zu gering erachtet. Orpheus wiederum kann seine Euridice letztlich nicht an ihm zweifeln sehen.

\section{Hinausgeschoben: Die Grenze zwischen Leben und Tod}

Die moderne Medizin mit ihren Möglichkeiten holt heute Menschen wieder ins Leben zurück, wie dies vor gar nicht so langer Zeit noch undenkbar war. Die Grenze zwischen Leben und Tod scheint manchmal beträchtlich hinausgeschoben worden. Der Umgang mit solchen Situationen und die Betreuung der oft stark beeinträchtigten Menschen werfen eine Unmenge an Fragen auf - ethische, psychologische und soziale. Was wissen wir tatsächlich darüber, wie Menschen im Wachkoma empfinden, welche Ängste und Fragen sie haben? Die Paralleldarstellerin der Euridice in Castelluccis Festwochenproduktion kann mit ihren Augen kommunizieren, sie stimmte der „Rol$1 \mathrm{l}^{\text {“ }} \mathrm{zu}$, in Absprache mit ihren Eltern. Wie weit dabei klar war, worum es geht und wie sie sich dann dabei gefühlt hat, entzieht sich der Kenntnis.
Etwa 800 bis 1000 Wachkomapatienten leben in Österreich - nach einem Unfall, einem Herzstillstand oder verursacht durch eine Hirnblutung oder einen Schlaganfall. Die Kommunikation ist mit einem Mal unterbrochen. Die Angehörigen sind hin und her gerissen in ihrer Sorge und ihrem Wunsch, nichts unversucht zu lassen, um das Leben des Schwerkranken zu verlängern, dem Gefühl der Hilflosigkeit und der eigenen Überforderung. Man spricht auch nicht gerne darüber - das Tabu ist weiterhin aufrecht. Ärzte reagieren im allgemeinen mit Professionalität - sachlich, sich an „Fakten“ wie den Vitalwerten orientierend und die eigene Hilflosigkeit häufig mit Distanz überspielend.

Abgesehen von einer großartigen, sehr berührenden Interpretation des großen Mythos von Orpheus und Euridike hat Regisseur Castellucci mit seiner Spiegelung in die Gegenwart etwas ganz Wesentliches aufgezeigt: Demut vor dem Leben, vor dem Tod und vor den Zwischenstufen, die uns alle irgendwie und irgendwann betreffen

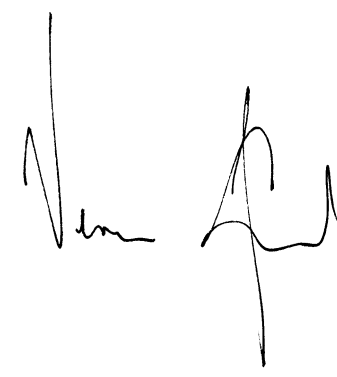

meint Ihre

Verena Kienast

Springer-Verlag GmbH

SpringerMedizin/Editor

verena.kienast@springer.at 